\title{
Relative and absolute duration judgments under prospective and retrospective paradigms
}

\author{
DAN ZAKAY \\ Tel-Aviv University, Tel-Aviv, Israel
}

\begin{abstract}
A dual-process contingency model of short duration judgment is proposed and tested. The first process, or $P(t)$, is a timer that uses cognitive capacity to keep track of units of time. If capacity is directed toward other tasks, $\mathrm{P}(\mathrm{t})$ will record fewer units and produce lower time judgments than when capacity is not directed toward other tasks. This timing process is most likely to affect performance when people know in advance (prospective judgments) that time judgments will be required and when absolute, rather than relative, judgments are made. The second process, or $\mathrm{P}(\mathrm{m})$, which is used for retrospective and relative judgments, judges duration on the basis of the number of remembered high priority events (HPEs) occurring during the interval. When this process is used, time judgments increase with the amount of HPEs that can be retrieved at the moment of judgment. Two experiments are reported. Tactual stimuli were presented, and nontemporal information processing load (simple or complex stimuli), type of judgment (absolute or relative), and judgment paradigm (prospective or retrospective) were manipulated. The results obtained support the proposed dual-process contingency model.
\end{abstract}

The perception of short durations is essential to developing a faithful representation of the external environment and is considered to be a cognitive process that utilizes available information judged to be relevant for representing specific durations (Aschoff, 1984; Block, 1990; Jackson, 1990). The present paper attempts to clarify the cognitive processes mediating short-duration judgment.

\section{Current Cognitive Models of Duration Judgment}

Memory-based models. According to these models, time judgments depend on information stored in memory. According to the storage-size model (Ornstein, 1969), time judgment is a function of the amount of information processed during a judged interval. As the amount and complexity of processed information increases, so does the size of memory storage, thus producing longer time judgments (see, e.g., Thomas \& Brown, 1974; Vroon, 1970). The storage-size model has been criticized (Block, 1990), however, because it relies on vague and unmeasurable constructs.

An alternative model proposed by Block $(1978,1989)$ contends that duration judgments are correlated with the number of changes in cognitive context during a judged interval. These changes might reflect environmental variations as well as alterations in cognitive strategies or emotional states. Accordingly, judged duration is a positive

The author extends his gratitude to $\mathrm{H}$. Ben-Shalom for her valuable help in conducting the experiments and to R. A. Block, L. E. Krueger, and two anonymous reviewers for their valuable comments. Correspondence should be addressed to D. Zakay, Department of Psychology, Tel-Aviv University, Ramat-Aviv 69978, Israel (e-mail: dzakay@ccsg.tau.ac.il). monotonic function of the number of contextual changes coded in memory (see, e.g., Block \& Reed, 1978).

The segmentation model (Poynter, 1983, 1989) elaborates on the contextual change model. Empirical findings (see, e.g., Poynter \& Homa, 1983; Zakay \& Feldman, in press) indicate that the more an interval is segmented by high-priority events (HPEs), such as contextual changes, the longer its judged duration.

All memory-based models generate the same major prediction-namely, a positive monotonic relationship between the magnitude of the judged duration of an interval and that of each of the following factors: task complexity, nontemporal information processing load, and number of contextual changes, or HPEs, occurring during a to-be-judged interval.

Capacity models. According to these models, duration judgments are primarily a function of the amount of temporal information processed by a timer (Berlyne, 1966) whose operation requires cognitive capacity. This capacity is shared with processes of nontemporal information processing. Thus, the fewer the number of temporal units processed by the timer, the lower the judged duration (see, e.g., Grondin \& Macar, 1992; Hicks, Miller, Gaes, \& Bierman, 1977; McClain, 1983; Zakay, 1989, 1992a, 1993; Zakay, Nitzan, \& Glicksohn, 1983). This predicts a negative monotonic relationship between nontemporal task complexity and its judged duration but cannot account for a positive relationship.

An integrative model. Thomas and Weaver (1975) argued that each stimulus is analyzed by two processors, a timer, $P(t)$, that processes temporal information and an information processor, $\mathrm{P}(\mathrm{I})$. Attention is divided between $P(t)$ and $P(I)$ according to task requirements, and duration judgment is a joint function of the two processors. 
The contribution of each is proportional to the amount of attention allocated to it, as described in Equation 1.

$$
\mathbf{E}=\alpha[\mathbf{P}(\mathbf{t})]+\beta[\mathbf{P}(\mathbf{I})],
$$

where $\alpha$ and $\beta$ are the corresponding weights, and $\mathrm{E}$ is the magnitude of a duration judgment. Nevertheless, this model lacks an explicit specification of the conditions governing the proportional allocation of resources to each processor. Furthermore, the model does not explicate the nature of the contribution of $P(t)$ and $P(I)$.

Event-structure models. Jones and Boltz (1989) and Boltz (1991) suggested that time judgments are a function of the difference between an actual and expected duration, and the intensity of temporal information processing. Temporal information processing is reflected by activities (such as grouping or counting) that are governed by the structure of events occurring during a target interval (i.e., hierarchical or nonhierarchical events).

This model provides a comprehensive explanation for determinants of temporal information processing and clarifies the role of expectations in duration judgment. However, it does not account for the influence of nontemporal information processing load.

\section{In Search of a Comprehensive Model}

Given the limitations of the models presented above, a comprehensive model meeting the following requirements is needed. The model should articulate the conditions under which either a positive or a negative relationship between magnitude of judged durations and corresponding nontemporal information processing load will be obtained. It should also account for the influence of the level of stimulus complexity and the number of contextual changes occurring during a judged interval. To meet these requirements, the contingency nature of duration-judgment processes should be explored.

\section{Duration Judgment as a Contingency Process}

Block $(1989,1990)$ identified four types of factors that interact to influence temporal experiences: (1) The kind of temporal behavior involved in terms of the type of time judgment utilized and the temporal dimension (e.g., order or duration) to be considered; (2) the nature of external or internal events that occur during a judged duration (e.g., the number, content, complexity, and modality of events, as well as their structure); (3) the characteristics of the experiencer; and (4) activity during a judged interval (e.g., nontemporal information processing load, etc.). The instructions to either prospectively or retrospectively judge the interval are included in the fourth category. In the prospective case, subjects are told of the need to judge duration before the target interval is initiated, but in the retrospective case, subjects are asked to judge the duration only after the target interval is terminated.

The present research focuses on the factors of paradigm and method of the duration judgment, since these two factors (which according to Block, 1989, influence the activity and the temporal behavior during a judged inter- val) are considered to be most influential (see, e.g., Hicks, Miller, \& Kinsbourne, 1976; Zakay, 1989).

The duration-judgment paradigm. It is well accepted today that prospective and retrospective duration judgments are mediated by different cognitive processes (see, e.g., Block, 1992; Hicks, Miller, \& Kinsbourne, 1976; Zakay, 1989, 1992b). Zakay (1990) pointed out that in a prospective condition, attention is directed in real time to information related to the passage of time. In a retrospective condition, attention during a judged interval is focused mainly on nontemporal information processing; therefore, relevant information on which duration judgments can be based must be searched for in memory. It seems highly probable that prospective duration-judgment processes are based on real-time temporal information processing, such as grouping or counting of temporal elements (see, e.g., Jones \& Boltz, 1989). Retrospective duration judgment, on the other hand, is more likely to depend on processes of information retrieval.

The duration-judgment method. It is generally agreed that judgment of stimulus duration depends in part on the measurement method used (see, e.g., Bindra \& Waksberg, 1956; Block, 1989; Carlson \& Feinberg, 1970; Clausen, 1950; Doob, 1971; Hawkes, Ray, \& Hayes, 1974; Wallace \& Rabin, 1960). Allan (1979) concluded that no single method can claim consistent superiority in terms of accuracy of measurement.

Zakay (1990) distinguished between absolute and relative time-judgment methods. In relative duration judgment, the duration of a target interval is judged relative to the duration of another interval that serves as a standard. Absolute duration judgments, although involving comparison with an internal subjective time unit, occur without reference to another external interval. The relative and absolute judgment types differ in the memory processes required. Regardless of whether the first presented interval was the target or the standard, the former method requires retrieval of a representation from long-term memory. In an absolute duration judgment, on the other hand, such a retrieval is not required.

\section{A Dual-Process Contingency Model of Short Duration Judgment}

The dual-process contingency model is described by the following nine postulates:

1. Duration judgment can be based on information produced by a timer, $P(t)$, information produced by a memory-based process, $P(m)$, or on both sources of information. Duration judgment is a process in which a source of information is selected or in which information from both sources is integrated.

2. The contribution of $P(t)$ and $P(m)$ to the durationjudgment process depends on the degree of retrievability and attentiveness of each source. Retrievability refers to the ease of retrieving information from a specific processor at the moment of judgment. Attentiveness is mainly a function of the degree of attention allocated to a given processor during a target interval and the making of the 
duration judgment. High degree of retrievability is a necessary condition for either $P(t)$ or $P(m)$ to make any contribution to time judgment. The weight assigned to specific information derived from either $P(t)$ or $P(m)$ is a function of the degree of attentiveness of the processor.

3. $P(t)$ represents the number of temporal units processed at any given moment. This number is increased with the level of attention allocated to temporal information processing during a given interval.

4. When duration judgment is requested following the completion of a target interval, or when $P(t)$ is not easy to retrieve or when its degree of attentiveness is low, a process of memory search is initiated, and prominent information coded during the target interval is retrieved from memory storage. The retrieved prominent information represents mainly HPEs, which are discrete in nature, and other contextual changes occurring continuously during the target interval. The retrieved information is stored and counted in $\mathrm{P}(\mathrm{m})$.

5. Temporal information processing takes place at all times, but it is done intermittently when cognitive capacity is not directly focused at $P(t)$; hence, under such conditions, $P(t)$ is assigned a low degree of attentiveness.

6. $P(t)$ is easy to retrieve only immediately after the termination of a judged interval. It is set to zero as soon as a new meaningful interval begins, unless it was deliberately stored in long-term memory.

7. When duration judgment is prospective and relates to an interval that has just ended (absolute judgment), the content in $P(t)$ is easy to retrieve and its attentiveness level is high.

8. $\mathrm{P}(\mathrm{m})$ can be constructed at any time, and it is always easy to retrieve when constructed. However, its degree of attentiveness decreases with the level of attention allocated to nontemporal information processing during a target interval.

9. When duration judgment is relative, memory-based processes are activated, because the comparison has to rely on the retrieval of the first interval. In addition, the $P(t)$ representation of the first presented interval is not easy to retrieve when the second interval ends unless, of course, it was deliberately stored in memory.

\section{The Rules of Duration Judgment}

a. When the duration judgment is prospective and absolute (PA; see Figure 1A), P(t) is easy to retrieve and has a high attentiveness level, whereas $P(m)$ is not likely to be constructed. Thus, duration judgment is based solely on $P(t)$, and a negative relationship between nontemporal information processing load and magnitude of duration judgment is expected (see above Postulates 4-7).

b. Two versions of prospective-relative conditions are possible:

$b_{1}$. Prospective instructions precede the first interval. Here, $P(t)_{1}$ can be stored for comparison with $P(t)_{2}$ after the second interval. Thus, the pattern of duration judgments is expected to be similar to the prospectiveabsolute case. This condition was not tested in the present study and is presented here for the sake of completeness.

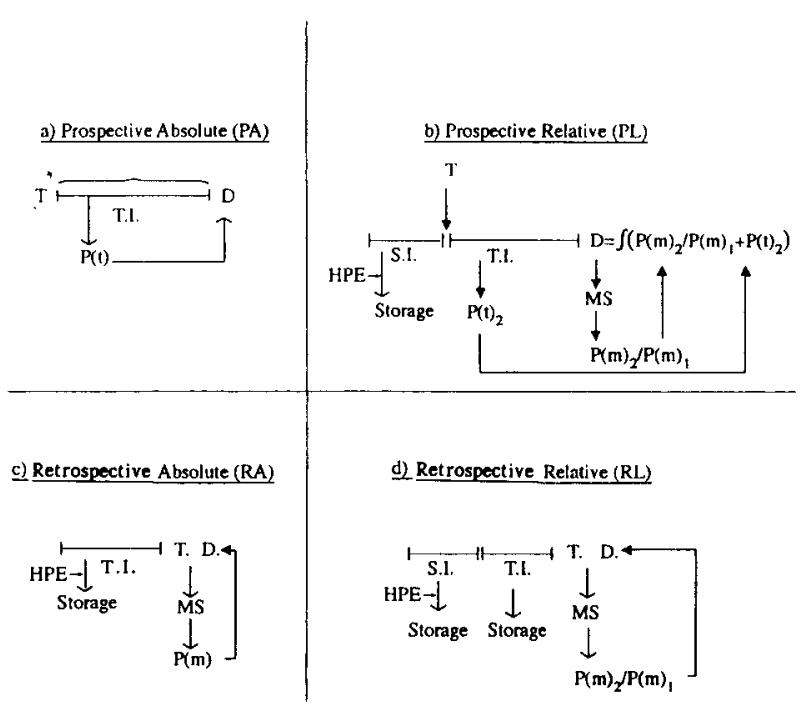

Figure 1. Duration judgment processes, according to the dualprocess contingency model. MS = memory search, $\mathrm{T}=$ instructions for duration judgment, $D=$ duration judgment, HPE = high priority events, T.I. = target interval, and S.I. = standard interval.

$b_{2}$. Prospective instructions follow the first (standard) interval but precede the second (target) interval (PL; see Figure 1B). Here, an integrative judgment process takes place. When the target interval is completed, $\mathrm{P}(\mathrm{t})_{2}$ is retrievable and has a high degree of attentiveness. On the other hand, the $P(t)$ representation of the first (standard) interval is not easy to retrieve. As a result, memory search takes place, and both $\mathrm{P}(\mathrm{m})_{1}$ and $\mathrm{P}(\mathrm{m})_{2}$ will be constructed in order to make the requested comparison. Duration judgment in this case is a function of the perceived ratio $P(m)_{2} / P(m)_{1}$ and of $P(t)_{2}$. When nontemporal information processing load during the target interval is high, $\mathrm{P}(\mathrm{t})_{2}$ is low, and the ratio of $\mathrm{P}(\mathrm{m})_{2} / \mathrm{P}(\mathrm{m})_{1}$ is high. However, when nontemporal information processing load during the target interval is low, $P(t)_{2}$ is high, and the ratio of $P(m)_{2} / P(m)_{1}$ is low. Therefore, the sum of the weighted average is similar in both cases, and the magnitude of duration judgments should be similar in both cases of high and low nontemporal information processing load.

c. When the duration judgment is retrospective and absolute (RA; see Figure 1C)-namely, it refers directly to that interval which has just ended- $P(t)$ is retrievable but its attentiveness level is low (see above Postulate 5). Thus, the pattern of retrospective absolute duration judgments should be similar to that of retrospective relative conditions.

d. When duration judgment is retrospective and relative (RL; see Figure 1D), $P(t)_{1}$ is not retrievable after the second interval is completed and $P(t)_{2}$ has a low attentiveness level (see above Postulate 6). Memory search processes are then initiated and duration judgment is based on a comparison between $P(m)_{2}$ and $P(m)_{1}$. A positive relationship between nontemporal information process- 
ing load during the target interval and magnitude of duration judgment is expected.

\section{Empirical Testing of the Model}

Overall experimental design. The contingency model was tested in two experiments comprising 16 experimental groups.

An absolute and a relative duration judgment method were used in Experiment 1 and Experiment 2, respectively. The two experiments were identical regarding all other aspects. In both experiments, the paradigm (prospective or retrospective) and the duration of the target interval (TI; 12 or $15 \mathrm{sec}$ ) were manipulated, as was the complexity of the tactual stimuli presented during the TI. A truly retrospective time judgment can be maintained only on the first trial of each subect (Zakay, 1990). On a second trial, awareness of time is already raised. Therefore, each subject participated only in one duration-judgment trial in all conditions. This constraint imposed a betweensubjects design. Thus, each experiment was designed as a $2 \times 2 \times 2$ (prospective or retrospective, 12 or $15 \mathrm{sec}$, and low vs. high stimulus complexity, respectively) complete between-subjects random factorial design.

\section{Subjects}

\section{METHOD}

Two hundred twenty-four first-year social science students at TelAviv University participated in the experiments in partial fulfillment of course requirements. There were 96 males and 128 females, with ages ranging from 19 to 28 years. None of the subects had participated in a previous time-perception experiment. All subjects had normal perceptual and motor abilities, were right-handed, and used their right hand in the experiment. The subjects were randomly allocated to each one of the 16 experimental groups generated by the factorial design. This was done separately for males and females so that 6 males and 8 females were tested in each group.

\section{Tactual Stimuli}

Two tactual stimuli, one simple and one complex, were used. The two geometrical figures (presented in Figure 2) are similar to those presented visually in Ornstein's (1969) experiments.

The ability to identify forms by touch has been demonstrated in previous research (see, e.g., Geldard \& Sherrick, 1986; Zakay \& Shilo, 1985). The task was to determine, using touch alone, the exact number of angles in a figure. The level of complexity was determined on the basis of information theory (see, e.g., Attneave, 1959). The more angles in the figure, the higher the information processing load for performing the task within a given time. Each figure was presented in relief on a $10 \times 10 \mathrm{~cm}$ cardboard card. Both the height of the relief above the cardboard and its width were $10 \mathrm{~mm}$.

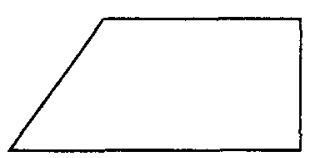

Simple

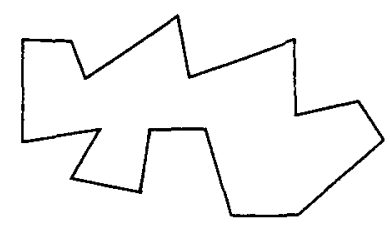

Complex
Figure 2. Geometrical figures employed as tactual stimuli.
Each relief was put inside a cardboard box $(20 \times 40 \times 40 \mathrm{~cm})$ with an opening $(12 \times 8 \mathrm{~cm})$ through which a subject could place his $/$ her right palm inside the box and touch the relief with the index finger. The durations of the TIs were selected on the basis of a pilot study that revealed that the average durations required for a correct counting were $11.03 \sec (n=10, S D=1.06)$ and $22.40 \sec (n=10$; $S D=3.2$ ) for the simple and complex figures, respectively.

Twelve- and 15-sec intervals were used as exposure times of tac tual forms in order to emphasize the two degrees of difficulty of the respective tasks. In the simple task, sufficient time was allocated; in the complex task, there was not enough time to complete the task. In addition, by testing two different intervals, more observations were attained for testing the hypotheses.

\section{Duration-Judgment Methods}

Relative duration judgment. The subjects were presented with two consecutive intervals. The first interval, serving as a standard interval, lasted for $10 \mathrm{sec}$ and was marked by the lighting of a red light bulb. The bulb measured $3.5 \mathrm{~cm}$ in width and $1.5 \mathrm{~cm}$ in height, with a 4-W intensity. It extinguished immediately when turned off, and therefore physical aftereffects were not expected.

Following the standard interval, the TI was presented, and the tactual task was performed. The TI was always the second interval to impose equality of conditions with absolute judgments. The onset and termination of the TI were demarked by two buzzes produced by a Sonalert buzzer (Mailory SE 623, 24 V, 3-14 mA) that lasted $0.5 \mathrm{sec}$ each. The buzzer was activated automatically by a hidden electronic timer. The subjects were asked to judge the TI's duration by comparing its duration with that of the red light. The subjects were shown two horizontal straight lines, drawn at the center of a $22 \times 28 \mathrm{~cm}$ piece of white paper. Each line was $26 \mathrm{~cm}$ long. On the upper line, a 13-cm section beginning at the left edge of the line was in boldface ( $1 \mathrm{~mm}$ wide). The subjects were told that the bold section represented the duration of lighting of the red bulb. They were asked to mark on the lower line $(0.5 \mathrm{~mm}$ wide), appearing $3 \mathrm{~cm}$ below, the exact length that represented the duration of the TI, relative to that of the red light. The length of lines provided equal probabilities for the subjects to mark the second interval as longer or shorter than the standard interval. The instructions were printed at the bottom of the judgment form.

Absolute duration judgment. The subjects were presented with the same two consecutive intervals described above. However, when asked to judge the duration of the TI, no reference was made to the first interval. The subjects were presented with the white paper with the two lines. The subjects were told that the $13-\mathrm{cm}$ bold section on the upper line representated a duration of $10 \mathrm{sec}$. They were asked to mark on the lower line the exact length that represented the duration of TI. The instructions were, again, printed at the bottom of the judgment form.

Controlling clock time durations. Durations of the standard and the TI intervals were controlled by a hidden electronic timer with a precision of $10 \mathrm{msec}$.

\section{Paradigm Manipulation}

Prospective paradigm. Before the onset of the TI, the subjects were told that they would be asked to judge its duration immediately upon termination. When the second buzz was sounded, either the relative- or the absolute-time-judgment form was provided. Thus, the tested conditions were PA and PL (see Figure 1).

Retrospective paradigm. The subjects were asked to judge the duration of the TI only after the second buzz was sounded, at which time the appropriate judgment form was given. The tested conditions were RA and RL (see Figure 1).

Experimental setting. The subjects were tested individually in an isolated chamber $(2 \times 2.5 \mathrm{~m})$, which was soundproof and lighted by a 40 -W fluorescent bulb. The subjects were seated in front of a table on which the cardboard box was placed. The chair's height 
was adjusted for each subject so that he/she could perform the tactual task conveniently. The red light bulb was placed above the box at a visual angle of $30^{\circ}$ upward.

\section{Procedure}

The subjects were told that they were participating in an experiment aimed at testing tactual performance. The subjects were then told that within the box there was a relief of a polygon and that their task was to count as accurately as possible the number of angles. The subjects were instructed to perform the task with the index finger of their dominant hand. The nondominant hand was held beneath the table. The reason given for that request was that the experiment was aimed at testing the influence of physical inconvenience on tactual performance. Actually, this manipulation was intended to keep the subjects from looking at their watches, which in all cases were worn on the nondominant hand. If the subjects had been asked directly not to look at their watches, their awareness of time would have increased. In that event, what was intended as a retrospective condition might actually have become a prospective one.

The subjects were then told that during the lighting of the red light bulb they could train themselves to recognize shapes by touching reliefs of a circle and an ellipse placed outside of the box. Carrying out these instructions required attending to the lighting of the bulb. After the red bulb was extinguished, the subjects received further instructions, which varied according to the experimental group. The prospective subjects were told again to determine tactually the number of angles in a hidden polygon and at the sounding of the second buzz to judge the duration of the task. The retrospective subjects were told to determine the number of angles, but duration-judgment instructions were not given. To eliminate periods of empty time, the subjects were ordered to move their finger over the relief continuously. Upon hearing the second buzz, the subjects removed their hands from the box. The prospective subjects received either a relative- or an absolute-duration-judgment form. Retrospective subjects were instructed to judge the duration of the target interval (the time starting and ending by a buzz) and received either a relative- or an absolute-duration-judgment form. After the duration judgment was completed, each subject was asked to provide a count of the number of angles and to state whether or not he/she was engaged continuously with the tactual task and to rate its level of difficulty on a 10-point scale, in which 1 stood for very easy and 10 for very difficult. In all cases, the subjects admitted to constantly being engaged with the tactual task.

\section{RESULTS}

The data were analyzed separately for the absolute and the relative time judgments. No sex differences were found on any dependent measure, and, for the sake of simplicity, they were excluded from the reported analyses.

\section{Absolute Duration Judgments}

Difficulty ratings. In all conditions, the complex polygon received significantly higher difficulty ratings than did the simple polygon. Mean ratings were $6.12(S D=$ $1.03)$ and $2.41(S D=0.98)$ for the complex and simple polygons, respectively. Only one main effect, that of polygon type, was found in a three-way analysis of variance (ANOVA) [paradigm $\times$ polygon type $\times$ duration; $F(1,104)=7.12, p<.01]$. Thus, support for the assumed difference in levels of nontemporal information processing load was obtained.

Duration judgments. The length of line marked by each subject was measured and taken as his/her duration judgment. Means and standard deviations of duration judgments are presented in Table 1 . The duration judgments were analyzed in a three-way ANOVA (paradigm $\times$ complexity $\times$ duration). Significant main effects of TI duration $[F(1,104)=7.92, p<.01]$ and of paradigm $[F(1,104)=7.11, p<.01]$, and a significant interaction between stimulus complexity and paradigm $[F(1,104)=$ $7.43, p<.01]$, were obtained. As shown in Figure 3, absolute duration judgments increased with information processing load under retrospective conditions and decreased when the paradigm was prospective. The differences between simple and complex duration judgments were significant only in the prospective paradigm in both the 12- and the 15-sec durations (Duncan multiple range tests, $p<.05$ and $p<.01$, respectively).

\section{Relative Duration Judgments}

Difficulty ratings. Again, under all conditions, the subjects assigned the complex polygon higher difficulty ratings than they assigned the simple polygon. Mean ratings for the relative groups were $6.36(S D=1.11)$ and 2.38 $(S D=1.01)$ for the complex and simple polygons, respectively. The only significant effect found for difficulty ratings in a three-way ANOVA was the main effect of polygon type $[F(1,104)=8.24, p<.01]$.

Duration judgments. Means and standard deviations of duration judgments are presented in Table 1. Duration judgments were analyzed in a three-way ANOVA. Significant main effects of TI duration $[F(1,104)=7.44$, $p<.01]$, stimulus complexity $[F(1,104)=4.61, p<$ $.05]$, and paradigm $[F(1,104)=4.13, p<.05]$ were obtained, as well as an interaction between stimulus com-

Table 1

Means and Standard Deviations of Absolute (A) and Relative (L) Duration Judgments (in Centimeters) According to Paradigm and Stimulus Complexity $(n=14$ in Each Cell)

\begin{tabular}{|c|c|c|c|c|c|c|c|c|c|c|c|c|c|c|c|c|}
\hline \multirow{5}{*}{$\begin{array}{l}\text { Duration } \\
\text { of Target } \\
\text { Interval } \\
\text { (in sec) }\end{array}$} & \multicolumn{16}{|c|}{ Paradigm } \\
\hline & \multicolumn{8}{|c|}{ Prospective } & \multicolumn{8}{|c|}{ Restrospective } \\
\hline & \multicolumn{4}{|c|}{ Simple } & \multicolumn{4}{|c|}{ Complex } & \multicolumn{4}{|c|}{ Simple } & \multicolumn{4}{|c|}{ Complex } \\
\hline & \multicolumn{2}{|c|}{ A } & \multicolumn{2}{|c|}{$\mathrm{L}$} & \multicolumn{2}{|c|}{ A } & \multicolumn{2}{|c|}{$\mathrm{L}$} & \multicolumn{2}{|c|}{ A } & \multicolumn{2}{|c|}{$\mathrm{L}$} & \multicolumn{2}{|c|}{ A } & \multicolumn{2}{|c|}{$\mathrm{L}$} \\
\hline & $M$ & $S D$ & $M$ & $S D$ & $M$ & $S D$ & $M$ & $S D$ & $M$ & $S D$ & $M$ & $S D$ & $M$ & $S D$ & $M$ & $S D$ \\
\hline $\begin{array}{l}12 \\
15\end{array}$ & $\begin{array}{r}8.88 \\
11.48\end{array}$ & $\begin{array}{l}2.68 \\
2.81\end{array}$ & $\begin{array}{r}8.72 \\
12.60\end{array}$ & $\begin{array}{l}1.25 \\
2.15\end{array}$ & $\begin{array}{l}6.32 \\
7.96\end{array}$ & $\begin{array}{l}2.21 \\
2.19\end{array}$ & $\begin{array}{r}9.92 \\
12.60\end{array}$ & $\begin{array}{l}2.19 \\
2.15\end{array}$ & $\begin{array}{l}10.09 \\
13.10\end{array}$ & $\begin{array}{l}2.64 \\
2.59\end{array}$ & $\begin{array}{r}9.20 \\
11.88\end{array}$ & $\begin{array}{l}1.67 \\
1.60\end{array}$ & $\begin{array}{l}12.11 \\
14.44\end{array}$ & $\begin{array}{l}2.15 \\
2.44\end{array}$ & $\begin{array}{l}11.92 \\
15.70\end{array}$ & $\begin{array}{l}2.25 \\
2.20\end{array}$ \\
\hline
\end{tabular}




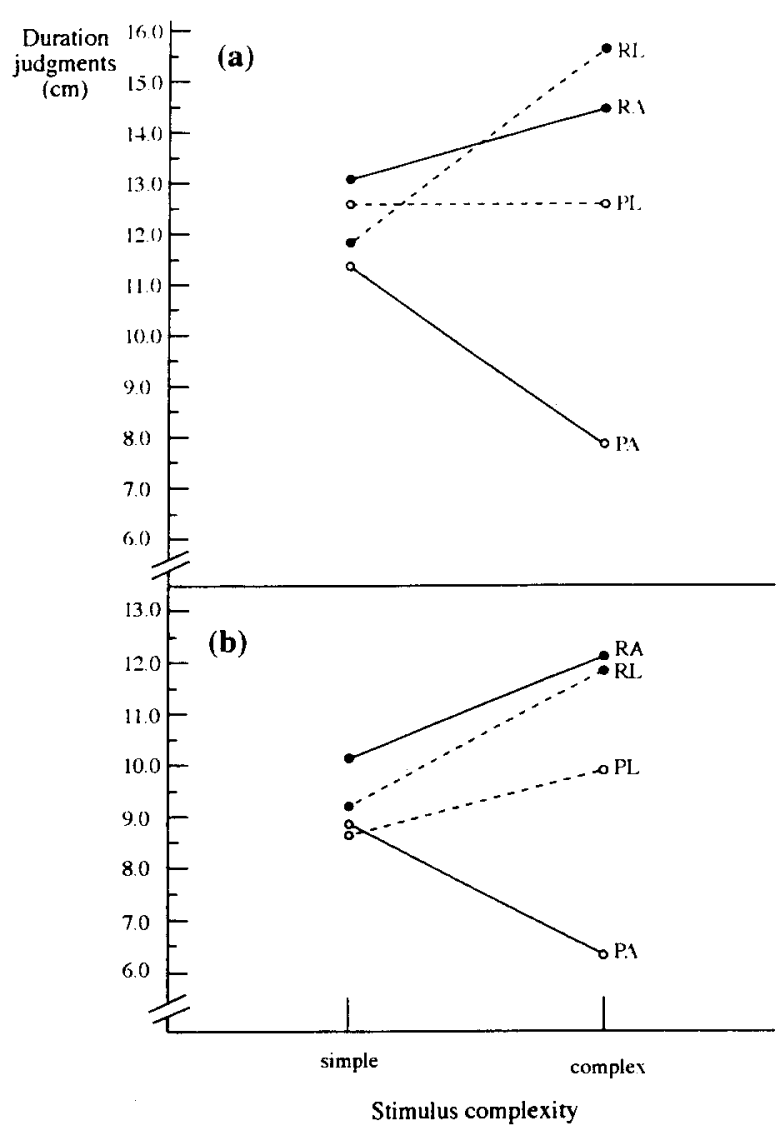

Figure 3. Interactions and main effects between paradigm, stimulus complexity level, and duration-judgment methods. (a) 15 -sec intervals, (b) 12-sec intervals. $R=$ retrospective, $P=$ prospective, $A=$ absolute, and $\mathrm{L}=$ relative.

plexity and paradigm $[F(1,104)=4.69, p<.05]$. As shown in Figure 3, retrospective relative duration judgments were significantly higher for the higher nontemporal information processing load conditions (Duncan test; $p<.01$ in both durations), but the differences between complex and simple conditions were significant for prospective judgments only in the 12-sec interval ( $p<$ .05). Similar patterns were found for absolute judgments.

\section{A Combined Analysis}

A four-way analysis reflecting the overall design (paradigm $\times$ judgment method $\times$ clock time $\times$ stimulus complexity) was used for analyzing the duration judgments obtained in the combined absolute and relative experiments. On the whole,time judgments were higher under retrospective conditions than under prospective conditions $[F(1,208)=4.43, p<.05]$ and were also higher for durations of $15 \mathrm{sec}$ than for durations of $12 \sec [F(1,208)=$ $6.81, p<.01]$. No significant differences were found for stimulus complexity and time-judgment methods $[F(1,208)=2.81$ and $F(1,208)=3.01$, respectively $]$. However, the interactions between paradigm and difficulty $[F(1,208)=7.14, p<.01]$, between paradigm and judgment method $[F(1,208)=5.12, p<.05]$, and the triple interaction between these three factors $[F(1,208)=$ $5.01, p<.05]$ were all significant. Although time judgments were on the whole higher for the simple than for the complex stimulus under prospective conditions, the opposite was the case under retrospective conditions. Under retrospective conditions, absolute and relative time judgments did not differ significantly in magnitude, but under prospective conditions, relative time judgments exceeded absolute ones. However, the triple interaction, in combination with the main effect of paradigm and the twoway interactions of paradigm with difficulty and paradigm with judgment method, indicates that only under PA conditions were time judgments significantly lower for the difficult than for the simple stimulus.

\section{DISCUSSION}

The present results lend support to the proposed dualprocess contingency model of short duration judgment. It was found that interactions for different combinations of paradigm, judgment method, and stimulus complexity yielded different patterns of duration judgments. The relationship between nontemporal information processing load (manipulated by stimulus complexity) and magnitude of duration judgments was positive under RL conditions but negative under PA conditions. For RA and PL conditions, however, the contingency model was only partially supported by the findings. Under RA conditions, the relationship between magnitude of duration judgments and stimulus complexity was positive for both the 12- and the 15 -sec intervals, respectively, but statistical significance was obtained only for the 12-sec interval. In the PL case, as predicted, no significant difference between magnitudes of duration judgments of the simple and complex stimuli was found for the 15-sec interval. However, for the 12sec interval, time judgments were higher for the complex than for the simple stimulus. Thus, the pattern of results of both the 12- and 15-sec intervals fits the model in the RL and PA conditions, but the picture regarding the magnitude of time judgments is less consistent in the RA and PL conditions. A possible explanation for this inconsistency is that time judgments in both the RA and the $\mathrm{PL}$ conditions involve both $\mathrm{P}(\mathrm{t})$ and $\mathrm{P}(\mathrm{m})$. Consequently, the exact magnitude of the final time judgment depends on the relative weight assigned to each processor. These weights are not constants and might fluctuate about some central value. Therefore, if the weights assigned to $P(m)_{1}$ and $P(m)_{2}$ exceed that assigned to $P(t)$, time judgments will be higher for complex than for simple stimuli under $\mathrm{PL}$ conditions. In the RA case, $\mathrm{P}(\mathrm{t})$ can contribute slightly to the overall duration judgment because it is easy to retrieve; on the other hand, its attentiveness level, and therefore its overall contribution, is low. This reduces the difference between magnitudes of duration judgments of simple and complex stimuli because $P(t)$ is higher for durations of simple than of complex stimuli, whereas the opposite is true for $\mathrm{P}(\mathrm{m})$. In the cases of RL and PA, the model predicts that only one processor contributes to the time judgment in each; therefore, they are not dependent on fluc- 
tuations in the weights' magnitudes. This is why duration judgments in both cases are more predictable.

Nevertheless, this does not make the model unfalsifiable. The dual-process contingency model is tested by the entire pattern of time judgments obtained in all conditions. In the RL and PA conditions, the model is evidently supported. In the RA and PL conditions, the relative magnitude of time judgments is not the only test of the model. An additional test concerns the difference between time judgments of the simple and complex stimulus $(\Delta \mathrm{T})$, which should have the following properties: (1) positive in the PA condition, (2) negative in the RL condition, and (3) intermediate in the RA and PL conditions. These properties were indeed obtained for both the 12-sec $(\Delta T=$ $2.56,-1.20,-2.02$, and -2.72 ), and the 15 -sec interval $(\Delta \mathrm{T}=3.52,0.00,-1.34$, and -3.82$)$, for the PA, PL, RA, and RL conditions, respectively. Therefore, the findings provide overall support for the model.

The combined analysis indicates that a model of duration judgments that does not take the interactions among contextual factors into account might be misleading. For instance, the lack of significant differences between simple and complex stimuli is an artifact. Only when the factors of paradigm and judgment method are considered can the true influence of stimulus complexity on time judgment be revealed.

Some clarifications regarding the role of memory and of on-line temporal information processing in the duration judgment process are appropriate at this time. It is clear that any stimulus input is constantly interfacing with associated memory representations, and this does not exclude the case of prospective conditions. Similarly, online processing of temporal information also occurs under retrospective conditions. However, the level of attention allocated to each process differs in each paradigm, and the use of information that exists in each processor reflects the allocated attention level. Temporal information processing is more intensive when (1) more cognitive capacity is allocated directly to temporal information processing, such as in the case when prospective instructions are given, (2) less cognitive capacity is required for nontemporal information processing during a judged interval, and (3) the structure of events occurring during the interval is more hierarchical and homogeneous (see, e.g., Jones \& Boltz, 1989) thereby producing easier and more intensive temporal information processing. This processing, which might be conscious or unconscious, is initiated by the grouping and counting of repetitive elements, such as beats of a piece of music, walking steps, and so forth. When it is difficult to perceive rhythmical elements during the to-be-judged interval (e.g., an "empty" interval), a deliberate counting strategy might be employed, as was shown even for young children (Levin \& Wilkening, 1989).

Whenever $P(t)$ is difficult to retrieve and has a low level of attentiveness, $\mathrm{P}(\mathrm{m})$ is constructed through a memory search process. The number of units of retrieved information counted in $P(m)$ is determined by the number of contextual changes perceived and processed during a target interval. The factors determining the number of changes are the following: (1) the richness of environmental and background stimuli (i.e., Block, 1982), (2) the required complexity of nontemporal information processing, and (3) ease of memory retrieval.

Most probably, the on-line processing of temporal information occurs in working memory. $\mathrm{P}(\mathrm{m})$, however, is most probably stored in memory only when a duration judgment is required. It could be assumed, therefore, that $P(m)$ is also constructed in working memory, but nevertheless remains a function of the information stored in long-term memory (LTM). Whereas $\mathrm{P}(\mathrm{m})$ can always be constructed, $P(t)$, which is produced in real time and is a function of real-time temporal information processing, will be lost and not retrievable in a later stage unless there is a special reason to store its content in LTM.

The on-line processing of temporal information apparently occurs under all circumstances, but its intensity depends on the degree of attention allocated to it. This degree yields a higher level of $P(t)$ attentiveness in a PA condition than in any other condition. Thus, there is a difference between the degrees of retrievability and of attentiveness. The two differ in that the former depends on memory processes whereas the latter depends on the degree of attention allocated during the target interval. $P(t)$ might have the same degree of retrievability in a PA condition as in an RA condition, but its attentiveness level is higher in PA.

The issue of how $P(t)$ and $P(m)$ are integrated in the production of duration judgment requires further elaboration. In one view, the process of integration is straightforward since both processors are counting units. Whereas $P(t)$ is a count of units derived from the temporal processing, $P(m)$ is a count of retrieved HPEs. Therefore, the integration is easily attained in the form of a weighted combination of both counts. A second view applies the judgmental heuristic of anchoring and adjustment (Tversky \& Kahneman, 1974) as an alternative to the integration process. In this view, the content of the processor that is most retrievable and highest in attentiveness level is used as the anchor for the duration judgment. The content of the other processor is used for adjusting the judgment with the degree of adjustment depending on the number of units counted in the process. For instance, in RA conditions, $P(m)$ serves as an anchor, whereas $P(t)$ might slightly increase the judgment in the case of a complex nontemporal task or even to a greater extent in the case of a simple task. In the case of PA, no adjustment occurs, because $P(m)$ is assumed to be nonexistent. Similarly, in the case of $R L, P(t)$, which is difficult to retrieve, is not expected to influence the duration judgment. Both of these explanations could be explored in further research.

Before concluding, a few points regarding the present findings require clarification. Most often, prospective duration judgments exceed retrospective ones (see, e.g., Block, 1992). In the present study, the opposite was found, and it appears to reflect the characteristics of the 
duration-judgment procedure employed. This procedure was specifically designed to produce a direct comparison of absolute and relative time judgments.

A second point concerns whether the findings can be generalized to clock times other than the 12- and 15-sec intervals employed here. As explained earlier, these particular intervals were selected in order to ensure the different degrees of difficulty of the experimental tasks. True, the difference of $3 \mathrm{sec}$ is minimal. Nevertheless, the monotonic relationship obtained between judged and objective time indicates that duration judgments were sensitive to the difference. In future research, however, a variety of time intervals should be examined.

To conclude, the dual-process contingency model outlined here resolves some inconsistencies existing in the duration-judgment literature. It provides a framework that can incorporate existing models that previously have been regarded as incompatible. The contingency model can also be applied to other paradigms in short-duration-judgment research, such as that of the "watched pot" (see, e.g., Block, George, \& Reed, 1980). In a "watched pot" experiment, intervals are judged to be longer when some prespecified event is expected to occur. An analysis of the contextual conditions in the "watched pot" situation revealed that it is a PA experiment, because subjects' awareness of time is raised by the instruction to wait for an event to occur, and the duration judgment is absolute and takes place immediately upon the termination of the target interval (Zakay, 1990). Also, nontemporal information processing is not required during the target interval. As a result, more attention is directed at $P(t)$ in the "waiting" condition, as compared with the "nonwaiting" condition, thus resulting in a higher duration judgment.

Of relevance to the present model is another phenomenon, the filled-interval illusion. Filled intervals are typically perceived as longer than equal empty intervals (see, e.g., Thomas \& Brown, 1974). This is true only when duration judgment is relative, either retrospective (RL) or prospective (PL). However, empty intervals should be perceived as longer when nontemporal information processing is required and the duration judgment is prospective and absolute (PA), as was indeed found in various studies (see, e.g., McClain, 1983; Poynter \& Homa, 1983; Zakay, Nitzan, \& Glicksohn, 1983). In the PA condition, time judgments are produced exclusively by $P(t)$. As explained earlier, when a target interval is empty, $P(t)$ will produce more time units than when the target interval contains stimuli evoking information processing.

Further research is needed in order to reveal more fully the determinants of the weights assigned to $P(t)$ and $P(m)$ and of the contextual nature of short-duration-judgment processes. In this respect, duration judgment seems similar to other judgmental processes, which have been shown by Payne (1982) and by Payne, Bettman, and Johnson (1988) to be contingent on situational factors.

\section{REFERENCES}

Allan, L. G. (1979). The perception of time. Perception \& Psychophysics, 26, 340-354.

Aschoff, J. (1984). Circadian timing. In J. Gibbon \& L. Allan (Eds.), Timing and time perception (Annals of the New York Academy of Sciences, Vol. 423, pp. 442-468). New York: New York Academy of Sciences.

ATTNEAVE, F. (1959). Applications of information theory to psychology. New York: Holt, Rinehart \& Winston.

BERLYNE, D. E. (1966). Effects of spatial order and inter-item interval on recall of temporal order. Psychonomic Science, 6, 375-376.

Bindra, D., \& WAKsBerg, H. (1956). Methods and terminology in the studies of time estimation. Psychological Bulletin, 53, 155-159.

Block, R. A. (1978). Remembered duration: Effects of event and sequence complexity. Memory \& Cognition, 6, 320-326.

BLock, R. A. (1982). Temporal judgments and contextual change. Joumal of Experimental Psychology: Learning, Memory, \& Cognition, 8 , 530-544.

BLock, R. A. (1989). Experiencing and remembering time: Affordance, context, cognition. In I. Levin \& D. Zakay (Eds.), Time and human cognition: A life span perspective (pp. 333-364). Amsterdam: NorthHolland.

BLock, R. A. (1990). Psychological models of time. In R. A. Block (Ed.), Cognitive models of psychological time (pp. 1-36). Hillsdale, NJ: Erlbaum.

BLOCK, R. A. (1992). Prospective and retrospective duration judgment: The role of information processing and memory. In F. Macar, V. Pouthas, \& W. J. Friedman (Eds.), Time, action and cognition (pp. 141-153). Dordrecht, The Netherlands: Kluwer Academic Publishers.

Block, R. A., George, E. J., \& Reed, M. A. (1980). A watched pot sometimes boils: A study of duration experience. Acta Psychologica, 46, 81-94.

Block, R. A., \& ReED, M. A. (1978). Remembered duration: Evidence for a contextual change hypothesis. Journal of Experimental Psychology: Human Learning \& Memory, 4, 656-665.

BolTz, M. (1991). Time estimation and attentional perspective. Perception \& Psychophysics, 49, 422-433.

Carlson, V. R., \& Feinberg, Z. (1970). Time judgment as a function of method, practice, and sex. Joumal of Experimental Psychology, 85, 171-180.

Clausen, J. (1950). An evaluation of experimental methods of time judgment. Joumal of Experimental Psychology, 40, 756-761.

Doos, L. W. (1971). Patteming of time. New Haven, CT: Yale University Press.

Geldard, F. A., \& Sherrick, C. E. (1986, July). Space, time and touch. Scientific American, pp. 84-89.

Grondin, S., \& MACAR, F. (1992). Dividing attention between temporal and nontemporal tasks: Preliminary results of a performance characteristic-POC-Analysis. In F. Macar, V. Pouthas, \& W. J. Friedman (Eds.), Time, action and cognition (pp. 119-129). Dordrecht, The Netherlands: Kluwer Academic Publishers.

HAWKES, G., RAY, W., \& HAYES, R. L. (1974). Judgment of stimulus duration with a competing task requirement. Journal of AuditoryResearch, 14, 187-191.

Hicks, R. E., Miller, G. W., Gaes, G. , \& Bierman, K. (1977). Concurrent processing demands and the experience of time in passing. American Journal of Psychology, 90, 413-446.

Hicks, R. E., Miller, G. W., \& Kinsbourne, M. (1976). Prospective and retrospective judgments of time as a function of amount of information processed. American Journal of Psychology, 89, 719-730.

JACKSON, J. L. (1990). A cognitive approach to temporal information processing. In R. A. Block (Ed.), Cognitive models of psychological time (pp. 153-180). Hillsdale, NJ: Erlbaum.

JoNEs, M. R., \& BolTz, M. (1989). Dynamic attending and responses to time. Psychological Review, 96, 459-491. 
Levin, I., \& Wilkening, F. (1989). Measuring time via counting. In I. Levin \& D. Zakay (Eds.), Time and human cognition: A life span perspective (pp. 119-144). Amsterdam: North-Holland.

MCCLAIN, L. (1983). Interval estimation: Effect of processing demands on prospective and retrospective reports. Perception \& Psychophsics, 34, $185-189$.

ORNSTEIN, R. E. (1969). On the experience of time. Middlesex, U.K.: Penguin.

Payne, J. W. (1982). Contingent decision behavior. Psychological Bulletin, 92, 382-402.

Payne, J. W., Bettman, J. R., \& Johnson, E. J. (1988). Adaptive strategy selection in decision making. Journal of Experimental Psychology: Learning, Memory \& Cognition, 14, 534-552.

POYNTER, W. D. (1983). Duration judgment and the segmentation of experience. Memory \& Cognition, 11, 77-82.

PoYNTER, W. D. (1989). Judging the duration of time intervals: A process of remembering segments of experience. Inferring time's passage. In I. Levin \& D. Zakay (Eds.), Time and human cognition: $A$ life span perspective (pp. 305-322). Amsterdam: North-Holland.

Poynter, W. D., \& Homa, D. (1983). Duration judgment and the experience of change. Perception \& Psychophysics, 33, 548-560.

Thomas, E. A. C., \& Brown, I., JR. (1974). Time perception and the filled-duration illusion. Perception \& Psychophysics, 16, 449-458.

Thomas, E. A. C., \& Weaver, W. B. (1975). Cognitive processing and time perception. Perception \& Psychophysics, 17, 363-367.

TVERSKY, A., \& KAHNEMAN, D. (1974). Judgment under uncertainty: Heuristics and biases. Science, 185, 1124-1131.

VROON, P. A. (1970). Effects of presented and processed information on duration experience. Acta Psychologica, 34, 115-121.
Wallace, M., \& Rabin, A.(1960). Temporal experience. Psychological Bulletin, 57, 213-233.

ZAKAY, D. (1989). Subjective time and attentional resource allocation: An integrated model of time estimation. In I. Levin \& D. Zakay (Eds.), Time and human cognition: A life span perspective (pp. 365-398). Amsterdam: North-Holland.

ZAKAY, D. (1990). The evasive art of subjective time measurement: Some methodological dilemmas. In R. A. Block (Ed.), Cognitive models of psychological time. (pp. 59-84). Hillsdale, NJ: Erlbaum.

ZAKAY, D. (1992a). On prospective time estimation, temporal relevance and temporal uncertainty. In F. Macar, V. Pouthas, \& W. J. Friedman (Eds.), Time, action and cognition (pp. 109-119). Dordrecht, The Netherlands: Kluwer Academic Publishers.

ZAKAY, D. (1992b). The role of attention in children's time perception. Joumal of Experimental Child Psychology, 54, 355-371.

ZAKAY, D. (1993). Timing and method of subjective time-estimationdo they influence time estimates? Perception, 22, 91-101.

ZAKAY, D., \& FELDMAN, T. (in press). The role of segmentation and recallability in retrospective time estimation. Psychological Record.

Zakay, D., Nitzan, D., \& Gurcksohn, J. (1983). The influence of task difficulty and external tempo on subjective time estimation. Perception \& Psychophysics, 34, 451-456.

ZAKAY, D., \& SHILo, E. (1985). The influence of temporal and spatial variation on tactile identification of letters. Journal of General Psychology, 112, 147-152.

(Manuscript received March 23, 1992; revision accepted for publication April 28, 1993.) 